\title{
Chronic indwelling foley catheter, a risk factor for catheter associated urinary tract infection.
}

\footnotetext{
1. MBBS, FCPS (Urology) Senior Registrar Urology DHQ Hospital, Faisalabad.

2. MBBS, FCPS (Urology)

Senior Registrar Urology \& Renal

Transplantation

Allied Hospital, Faisalabad.

3. MBBS, FCPS (Urology)

Senior Registrar Urology

DHQ Hospital, Faisalabad.

4. MBBS, FCPS (Urology)

Associate Professor Urology,

Allied / DHQ Hospital,

Faisalabad Medical University,

Faisalabad.

5. MBBS, MS (Urology)

Professor Urology

Allied / DHQ Hospital,

Faisalabad Medical University,

Faisalabad.

6. MBBS, MS (Urology)

Professor Urology

Independent University Hospital,

Faisalabad.
}

Correspondence Address:

Dr. Muhammad Saifullah

Department of Urology

DHQ Hospital, Faisalabad.

drsaif1987@gmail.com

Article received on:

15/05/2020

Accepted for publication:

30/07/2020

\section{INTRODUCTION}

Catheter associated infection is one of commonest infection which affects hospital admitted patients. ${ }^{1}$ Urinary catheter is the most commonly used indwelling device. Indwelling catheter is responsible for approximately $70-80 \%$ of urinary infections. ${ }^{2}$ Indwelling urethral catheters which are kept in place for 30 days or less are called short term. Whereas, when catheter placement exceeds 30 days, it is known as chronic or long term. Catheter associated urinary tract infection (CAUTI) is assigned to catheterized individuals having symptoms like fever and suprapubic pain. $50 \%$ of bacteremia episodes are preceded by CAUTI in long-term healthcare facilities. ${ }^{3} 60 \%$ of CAUTI episodes can be prevented using evidence based prevention practices. ${ }^{4}$ Patients having urethral catheter in situ harbour 3-36 times more risk of bacteremia than the individuals without an indwelling catheter. ${ }^{5}$ Apart from CAUTI urethral catheters lead to many other infectious and non-infectious complications. Purulent urethritis, abscess formation and prostatitis are the infectious complications. ${ }^{5}$ Catheter blockage, bladder stones, urethral strictures, impaired mobility and mechanical trauma due to catheter contribute to non-infectious complications. ${ }^{6}$

Patients who are unable to void by themselves due to either bladder outlet obstruction or underactivity of detrusor muscle require chronic or long term catheterization. Individuals having severe incontinence, neuropathic bladder dysfunction due to spinal cord injury or paralyzed bed ridden patients may also require chronic catheterization in order to improve the quality of life. ${ }^{7}$ And this long term catheterization is an independent risk factor for CAUTI development. ${ }^{8}$ The incidence of UTIs among hospitalized patients with indwelling catheters is approximately $15 \%$ hospitalized 
patients develop urinary infection due to an indwelling urethral device. ${ }^{9}$

Culture of midstream specimen of urine remains the gold standard choice to diagnose a case of UTI. ${ }^{10}$ CAUTI is diagnosed using positive culture of urine with atleast $\geq 10^{5} \mathrm{CFU} / \mathrm{ml}$ or urine culture yielding $10^{3}$ to $10^{5} \mathrm{CFU} / \mathrm{ml}$ with positive urinalysis. Presence of microorganisms on gram stain or pyuria on urinalysis is labeled as positive urinalysis. ${ }^{1}$

By conducting this study, we can find out the magnitude of the commonest acquired infection amongst hospitalized individuals in the region i.e., CAUTI. In this way we can turn our attention towards changing the indwelling Foley catheters regularly and the use of external catheters in patients who don't have bladder outlet obstruction. Alternatively clean intermittent catheterization is another safe option for individuals having bladder outlet obstruction.

\section{MATERIAL \& METHODS}

This was a cross-sectional study conducted at department of Urology \& Renal transplantation of Allied Hospital, Faisalabad for a period 6 months between 01-12-2015 and 31-05-2016. Patients aged 15 - 70 years of either gender having a supra-pubic or urethral Foley catheter in situ for $>30$ days were enrolled for the study purpose. However, diabetic, immuno-compromised or patients who have taken antibiotics within the last 2 weeks were ruled out of the study.

After taking approval from the ethical review committee, total 100 patients were selected for the study and consent was obtained on a proforma for the investigations and use of data for research purpose. Under aseptic conditions, indwelling urethral catheter was replaced. The Foley catheter tip which we had taken out was cut and separated. It was delivered to the pathologist for culture and sensitivity in a secured axenic container. Diabetes was ruled out using blood sugar fasting levels. Data was recorded using a proforma. along with standard deviation was determined for all quantitative variables like age. Percentages and frequencies were determined for all qualitative variables like UTI and gender. Stratification was used to control effect modifiers like age and gender. Post-stratification chi-square test was applied. P-value $<0.05$ was taken as significant.

\section{RESULTS}

Out of 100 patients enrolled in the study, 53\% $(n=53)$ were aged below 50 years whereas $47 \%$ $(n=47)$ were aged above 50 years. Mean age was $46.45+12.39$ years. Majority $95 \%(n=95)$ of patients were male and only $5 \%(n=5)$ were females.

$18 \%$ cases $(n=18)$ having chronic indwelling urethral catheter were having UTI. However, $82 \%$ cases $(n=82)$ had no urinary tract infection. (Figure-1).

Patients having CAUTI were stratified in terms of age and gender. Table-I \& II show the distribution of patients according to age and gender respectively.

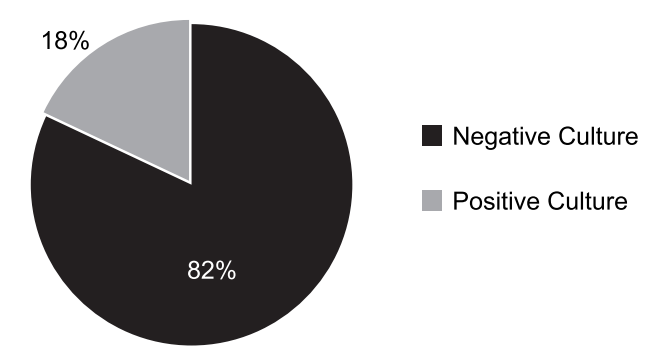

Figure-1. Distribution of patients according to culture.

\begin{tabular}{|c|c|c|}
\hline \multirow{2}{*}{$\begin{array}{c}\text { Age } \\
\text { (in years) }\end{array}$} & \multicolumn{2}{|c|}{ CAUTI } \\
\hline & Yes & No \\
\hline Below 50 & 11 & 42 \\
\hline Above 50 & 7 & 40 \\
\hline \multicolumn{3}{|c|}{ Table-I. } \\
\hline \multirow{2}{*}{ Gender } & \multicolumn{2}{|c|}{ CAUTI } \\
\hline & Yes & No \\
\hline Male & 17 & 78 \\
\hline Female & 1 & 4 \\
\hline
\end{tabular}

Data analysis was done using SPSS v-17. Mean 


\section{DISCUSSION}

CAUTI is a big matter of debate especially in developing countries. It is responsible for significant economic burden and utilizes valuable health resources. In our study, $18 \%$ patients having chronic urethral catheter were recorded to have UTI. Lee $\mathrm{JH}$ et al recorded the $15 \%$ prevalence of UTIs among individuals harboring Foley catheters. ${ }^{9}$ Whereas, Letica-Kriegel AS et al found that duration of indwelling urethral catheter is a risk factor for $16.5 \%$ episodes of CAUTI. Out of these $12 \%$ of patients develop CAUTI. ${ }^{11}$ These findings are in agreement with our study.

CAUTI rates increased in United States by $6 \%$ over 4 years between 2009 and 2013. ${ }^{11}$ CAUTI in intensive care units of NHSN hospitals has decreased by $18.5 \%-67 \%$ during $1990-2007 .{ }^{12}$ Venhems $\mathrm{P}$ reported a $66 \%$ reduction in CAUTI over 10 years in France. ${ }^{13}$ This decline is partially due to intense efforts taken for prevention, but most of it is a result of exclusion of asymptomatic bacteriuria from the definition of CAUTI. With every passing catheter day, risk of developing CAUTI increases by $5 \%{ }^{4}$

$3-10 \%$ of residents in United States are being managed using long term Foley catheters. ${ }^{14}$ Surveillance reports of European advocate presence of Foley catheters in 12\% residents of Dutch nursing homes ${ }^{15}, 12.3 \%$ in Italian nursing homes ${ }^{16}$ and $10.1 \%$ German nursing homes. ${ }^{17}$ In Swedish homes, prevalence of Foley catheters was $7 \%$. Among these $16 \%$ are men and only $3 \%$ are women. ${ }^{18}$ Patients with chronic Foley catheters have increased risk for developing symptomatic UTI. According to Stevenson KB et al, CAUTI rates 3.2/1,000 catheter days were seen in health care facilities of Idaho. ${ }^{19}$ Letica-Kriegel AS et al identified a rate of CAUTI as 1.64 per 1000 catheter-days. ${ }^{11}$ Incidence of febrile illness from a likely urinary device is 7-11/1000 catheter days, which is approximately three times more than the incidence in patients without a Foley catheter. ${ }^{20}$

Tambyah PA et al studied that 3\% of patients having catheter associated asymptomatic bacteriuria progress to bacteremia with the urinary pathogen.${ }^{21}$ However, CAUTI is the most common etiological factor which lead to bloodstream infection in health care facilities. In Quebec study, $21 \%$ of hospital acquired hematological infections were attributable to a urinary source. Mortality in individuals diagnosed with CAUTI and subsequent development of bacteremia was $15 \% .{ }^{22}$

In summary, the CAUTI rates which were determined by our study have comparable results with other international studies. However, more studies with bigger sample size are required for further establishment of facts.

\section{CONCLUSION}

It is concluded that urinary infection rate is definitely higher among patients with chronic Foley catheters in our population possible due to poor hygiene and improper catheter care. It is therefore required that every patient having indwelling catheter should be evaluated for possible urinary tract infection.

\section{RECOMMENDATIONS}

1. We recommend frequent and timely changing the indwelling Foley catheters or clean intermittent catheterization in patients with bladder outlet obstruction.

2. Bed ridden or unconscious patients who don't have any bladder outlet obstruction should be managed with external catheters instead of indwelling catheters.

\section{Copyright $\odot 30$ July, 2020.}

\section{REFERENCES}

1. Trautner BW. Management of catheter-associated urinary tract infection (CAUTI). Curr Opin Infect Dis. 2010; 23:76-82.

2. Hussein HA, Hassan LJ, Al-Alawachi SF, Al-Alawchi MSS, Al-Alawchi AS. Catheter associated urinary tract infections in pregnant women. JUBPAS. 2020Mar.11; 27:231-43.

3. Nicolle LE. Catheter associated urinary tract infections. Antimicrob Resist Infect Control. 2014; 3:23.

4. Taha H, Raji SJ, Khallaf A, et al. Improving catheter associated urinary tract infection rates in the Medical Units. BMJ Qual Improv Rep. 2017; 6(1):u209593. w7966. 
5. Nicolle LE. Urinary tract infections in the elderly. Clin Geriatr Med. 2009, 25:423-436.

6. Saint S, Trautner BW, Fowler KE, et al. A Multicenter Study of Patient-Reported Infectious and Noninfectious Complications Associated With Indwelling Urethral Catheters. JAMA Intern Med. 2018; 178(8):1078-1085.

7. Wilde M, McDonald MV, Brasch J, McMahon JM, Fairbanks E, Shah S, et al. Long-term urinary catheter users self-care practices and problems. J ClinNurs. 2013; 22:356-67.

8. Vincitorio D, Barbadoro P, Pennacchietti L, et al. Risk factors for catheter-associated urinary tract infection in Italian elderly. Am J Infect Control 2014; 42:898-901.

9. Lee JH, Kim SW, Yoon BI, Ha US, Sohn DW, Cho YH. Factors that affect nosocomial catheter-associated urinary tract infection in intensive care units: 2-year experience at a single center. Korean J Urol. 2013; 54:59-65.

10. Schmiemann G, Kniehl E, Gebhardt K, Matejczyk MM, Hummers-Pradier $E$. The diagnosis of urinary tract infection. DtschArztebl Int. 2010; 107:361-7.

11. Letica-Kriegel AS, Salmasian H, Vawdrey DK, Youngerman BE, Green RA, Furuya EY, Calfee DP, Perotte R. Identifying the risk factors for catheterassociated urinary tract infections: A large crosssectional study of six hospitals. BMJ Open. 2019 Feb 21; 9(2):e022137.

12. Burton DC, Edwards JR, Srinivasion A, Fredkin SK, Gould CV. Trends in catheter-associated urinary tract infections in adult intensive care units - United States, 1990-2007. Infect Control Hosp Epidemiol. 2011; 32:748-756.

13. Venhems P, Baratin D, Voirin N, Savey A, Caillat-Vallet E, Metzger M-H, Lepape A. Reduction of urinary tract infections acquired in an intensive care unit during a 10-year surveillance program. Eur J Epidemiol. 2008; 23:641-645.
14. Crnich CJ, Drinka P. Medical device-associated infections in the long-term care setting. Infect Dis Clin North Am. 2012; 26:143-164.

15. Eilers R, Veldman-Ariesen MJ, Van Bentham BH. Prevalence and determinants associated with healthcare-associated infections in long-term care facilities in the Netherlands, May to June 2010. Euro Surveill. 2012; 17(34):pil=20252.

16. Moro ML, Ricchizzi E, Morsillo F, Marchi M, Purs V, Zotti CM, Prato R, Privitera G, Poli A, Mora I, Fedeli U. Infections and antimicrobial resistance in long term care facilities: A national prevalence study. Ann Ig. 2013; 25:109-118.

17. Heudorf L, Boehicke K, Schade M. Healthcareassociated infections in long-term care facilities in Frankfurt am Main, Germany, January to March 2011. Euro Surveill. 2012; 17(35):pil=20256.

18. Jonsson K, Loft A-L E, Nasic S, Hedelin H. A prospective registration of catheter life and catheter interventions in patients with long-term indwelling catheters. Scand J Urol Nephrol. 2011; 45:401-403.

19. Stevenson KB, Moore J, Colwell H, Sleeper B. Standardized infection surveillance in long-term care: Interfacility comparisons from a regional cohort of facilities. Infect Control Hosp Epidemiol. 2004; 25:985-994.

20. Nicolle LE. Urinary catheter associated infections. Infect Dis Clin North Am. 2012; 26:13.28.

21. Tambyah PA, Maki DG. Catheter-associated urinary tract infection is rarely symptomatic. Arch Intern Med. 2000; 160:678-687.

22. Fortin E, Rocher I, Frenette C, Temblay C, Quach C. Healthcare-associated bloodstream infections secondary to a urinary focus: The Quebec Provincial Surveillance results. Infect Control Hosp Epidemiol. 2012; 33:456-462. 


\begin{tabular}{|c|c|c|c|}
\hline \multicolumn{4}{|c|}{ AUTHORSHIP AND CONTRIBUTION DECLARATION } \\
\hline Sr. \# & Author(s) Full Name & Contribution to the paper & Author(s) Signature \\
\hline 1 & Muhammad Saifullah & $\begin{array}{l}\text { Principal author, Data collector } \\
\text { and manuscript writer. }\end{array}$ & \\
\hline 3 & Hanan Noor & Literature review and Data & \\
\hline 4 & Muhammad Akmal & Proof reading. & \\
\hline 5 & Ghulam Mehboob & Research supervisor. & \\
\hline 6 & $\begin{array}{l}\text { Subhani } \\
\text { Safdar Hassan Javed }\end{array}$ & Research supervisor. & \\
\hline
\end{tabular}

